\title{
Developing English Critical Reading Comprehension Ability Using SIOP and Inquiry Learning Approach for Secondary Students
}

\author{
Natchaya Raksa* Denchai Prabjandee Parinya Thongsorn \\ Faculty of Education, Burapha University, Thailand
}

\begin{abstract}
The objectives of this study were 1) to develop English critical reading comprehension ability using the SIOP and the inquiry learning approach for secondary students and 2) to investigate attitudes toward the approach after using SIOP and inquiry learning approach. The participants were 35 students from secondary school, selected using random cluster sampling. The instruments employed in the study were the lesson plans, English critical reading comprehension ability tests, and attitude questionnaires for exploring the students' attitudes toward learning provision using SIOP and the inquiry learning approach. The data analysis was interpreted from both qualitative and quantitative sources. The findings of this research were firstly that the testing scores after using the approach were statistically higher than before using at the .05 level. Secondly the overall result of the students' attitudes toward learning provision using SIOP and inquiry learning approach was at the agree level.
\end{abstract}

Keywords: English critical reading/ SIOP approach / inquiry learning approach

DOI: $10.7176 / \mathrm{JEP} / 11-33-14$

Publication date: November $30^{\text {th }} 2020$

\section{Introduction}

Although reading comprehension plays a significant role and has been promoted in an ongoing process among Thai people, the majority of them still do not like reading. This is aligned with the survey statistics presented by the National Statistical Office of Thailand in relation to reading, stating that there are about 22.4 million people or approximately $40 \%$ of the total population who do not read books. Of these numbers, the statistics reveal that $60 \%$ of young children aged $10-14$ claimed that they do not like to read. This is more likely to cause serious problems for Thai students and it is found that their reading ability was rated in the lower level, scoring only two out of five. There may be many reasons behind this phenomenon; however, the main reason is that teachers employ inappropriate teaching approaches which lead to a lack of success and achievement in reading for the students and those teaching approaches. In addition, those teaching approaches may not enhance student's opportunity to learn skills and develop their reading ability. Therefore, teachers may consider changing their teaching approaches to teach students how to read and develop reading skills; for example, critical reading comprehension skill.

The aspect of English reading in which Thai students require immediate improvement is their critical skills. Thai students are mainly encouraged to learn through recitation, they lack a wide range of opportunity to think, analyse, and explore things by themselves. Hence, for English teaching and learning in Thailand, it is essential to encourage students to learn through their frequent practices and various learning activities and processes such as the process of promoting critical reading comprehension by focusing mainly on learners. Ruddell (1977) stated that reading skill can develop students in terms of critical skills by asking questions, it is the most stimulating method for encouraging students to think. Questions can lead students to think and review their understanding and try to seek answers. Moreover, their study found that a provision of learning which helped enhance English critical reading comprehension ability was applied through SIOP. Similarly, Sydney (2014) pointed out that students' learning achievements in English were higher after the application of SIOP.

Therefore, learning provision using SIOP shall be taken into account in developing English critical reading comprehension ability. Moreover, Llewellyn (2013) stated that inquiry approach is a learning process which uses asking questions and finding answers using scientific process. The researchers of this study, as English teachers, see the importance of developing English skill, especially reading skill. This may enhance students' reading skill to be more effective. The research aimed to develop English critical reading comprehension ability using SIOP and inquiry learning approach for secondary students. This may help improve students' English critical reading comprehension skill and lead to higher learning achievement performance. This includes applying English critical reading comprehension skill in their daily life in the future.

\section{The study}

This study was to develop English critical reading comprehension ability using the SIOP and inquiry learning approach for secondary students and to investigate attitudes towards the approach after using SIOP and the inquiry learning approach. 


\subsection{Participants}

The population of this study were the four classrooms of secondary students from one of the largest schools in Chonburi province. The sample group was selected using random cluster sampling, which was one of the classrooms consisting of 35 students. The data collection was carried out during the first semester of the academic year 2020 .

\subsection{Procedure}

This study was undertaken in four stages, as outlined below:

Stage 1: to study basic knowledge of English reading comprehension problems of secondary students

1.1 To explore the basic knowledge and relevant literature about critical reading comprehension

1.2 To identify problems relating to English critical reading comprehension of secondary students, in order to seek for appropriate teaching approaches

1.3 To examine the SIOP concept and inquiry learning approach

After reviewing relevant literature about critical reading comprehension and integrating the literature as 8 components of SIOP approach (Echevarria et al., 2011) and 5 components of Inquiry approach (Lawson, 1995, p.164 - 165). I synthesize 6 components of teaching as display as Figure 1:

\begin{tabular}{|c|c|c|}
\hline SIOP Approach & Teaching Synthesis & Inquiry Approach \\
\hline \multicolumn{3}{|l|}{ 1. Preparation } \\
\hline \\
\hline \multicolumn{3}{|c|}{ 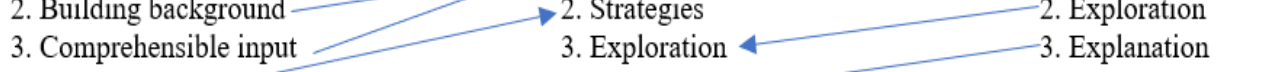 } \\
\hline \multicolumn{3}{|c|}{ 4. Strategies $\longrightarrow$ 4. Explanation $\longrightarrow$ 4. Elaboration } \\
\hline \multicolumn{3}{|c|}{ 5. Interaction $\longrightarrow$ 5. Elaboration and Lesson delivery 5 . Evaluation } \\
\hline \multicolumn{3}{|c|}{ 6. Practice and Application $\longrightarrow$ 6. Review and Evaluation } \\
\hline & & \\
\hline evlew & & \\
\hline
\end{tabular}

Figure 1: Synthesize SIOP approach and Inquiry approach

Stage 2: to design teaching process for English critical reading comprehension ability by using SIOP and inquiry learning approach by developing teaching material and creating research instruments

2.1 To develop teaching approaches for English reading comprehension by focusing on designing a teaching process for English critical reading comprehension ability by using SIOP and the inquiry learning approach

2.1.1 To synthesize the teaching principles by basing them on SIOP and inquiry learning approach

2.1.2 To develop the teaching development process retrieved from the synthesis

2.2 To prepare and create teaching material and documents

2.2.1 To review literature such as SIOP concept, inquiry learning approach, and the Foreign Language Learning Curriculum

2.2.2 To analyse and outline learning outcomes

2.2.3 To create plans for a provision of learning English critical reading comprehension

2.2.4 To design an achievement test for English critical reading comprehension ability

2.3 To develop the quality of instruments

2.3.1 To instrument value determined by experts

2.3.2 To improve the instrument as per the experts' suggestions

Stage 3: to apply with the sampled group of secondary students

3.1 To carry out the pre-test for the students' English critical reading comprehension ability

3.2 To implement the synthesized teaching process in the classroom

3.3 To carry out the post-test for the students' English critical reading comprehension ability

3.4 To investigate the students' attitudes toward learning provision by using the attitude questionnaire Stage 4: to evaluate its effectiveness

4.1 English critical reading comprehension before and after implementation

4.2 Attitude toward learning provision

\subsection{Data analysis}

To carry out the pre-test for the students' English critical reading comprehension ability by synthesized teaching process in the classroom. To investigate the students' attitudes toward learning provision using the attitude questionnaire.

\section{Findings}

The study revealed that the students' average score for their achievement in the pre-test was 15.23 and for the posttest was 17.37. The standard deviation valued 3.08 and 3.73 respectively. From the T Dependent samples test, T- 
value was 5.12. This concluded that the mean score from the post-test was higher than the pre-test score by the significant level of .05

The study also indicated that the secondary students had "agree" attitude toward learning provision using SIOP and inquiry learning approach. From the in-depth data analysis, it was shown that the majority of the students perceived that "English critical reading comprehension has benefits for furthering higher education level", with the average score 4.54. The second largest groups of the students were illustrated through two attitudes. The first one was that the students thought that learning activities of English critical reading comprehension allowed them to have more opportunity for self-learning, where the mean was 4.29. Another attitude was that they enjoyed learning and could gain knowledge from English critical reading comprehension teaching $(\overline{\mathrm{x}}=4.26)$. On the contrary, the students mentioned that they could not really reflect what thoughts were taken into account from the researcher after finishing this class $(\overline{\mathrm{x}}=3.66)$.

\section{Conclusion}

The appropriate teaching process was obtained which focused on developing the English reading comprehension ability of the secondary students using SIOP and the inquiry learning approach. The researcher employed the SIOP concept consisting of eight methods which can also be used as the instrument in systematic learning provision. This could enhance students' understanding and development in English learning, including their language learning skill and learning achievement. By implementing the inquiry learning approach, it involves learning provision with five steps which is synthesized from a number of academics where teachers implement learning activities by setting up questions for students. To be explained in-depth, this process requires teachers to stimulate students by posing questions or creating scenarios that will encourage students to think and develop their cognitive process. From this procedure, after the synthesis process, teachers are more likely to be able to develop their systematic and quality teaching processes. This helps enhance English critical reading comprehension ability of secondary students.

The researcher started the teaching approach development process by exploring problems, basic knowledge, and teaching process from different perspectives. The next step was to synthesize and propose to the chairman and the committee to evaluate and review. Later, the research took into account all suggestions and comments from the committee when developing and designing the teaching process for English critical reading comprehension. After that, the teaching process was evaluated through the index of item-objective congruence by five experts. Before implementing this with the sample group, the research finalized the instrument by taking into consideration all the comments from those experts and made any necessary changes to the instrument in order to make it more effective. The instrument was applied to another group of students for the pilot study before implementing with the sample group due to the instrument's quality assurance.

Comparison of secondary students' English critical reading comprehension ability between before and after learning provision using SIOP and the inquiry learning approach showed that the students' average score for their achievement pre-test was 15.23 and for the post-test was 17.37. The average score from the achievement post-test was higher than the pre-test score with the significant margin of .05 . The study claimed that learning provision involving SIOP concept and the inquiry learning approach through learning activities were more likely to be able to encourage students to think, analyse, pose questions, explore, practice self-study, and seek answers for themselves. Therefore, the students' learning achievement after implementing the teaching process using SIOP and the inquiry learning approach was higher than the pre-test one with significant difference of .05. This is aligned with Short (2011, p.363) study, suggesting that teaching a group of students by using SIOP had the statistically significant value in terms of English reading comprehension ability when comparing to the other group which did not. In 2012, Short further explained that teaching English as a second language in Northern Jersey using SIOP enhanced students' learning ability and improved students' English language learning achievement. Similar to Thomas (2012), implementing SIOP to teach students by using English language as a medium for Sciences enhanced students' learning achievement. Likewise, Sydney (2014) indicated that students' learning achievement in English of primary students was higher after the implementation of SIOP. Another study from Supa-uthomporn (2016) stated that using five learning steps technique in Science class helped enhance cognitive ability of Lower Secondary students at Chulalongkorn University Demonstration School, with the significant level of .05.

Overall, the attitudes of secondary students toward learning provision using SIOP and inquiry learning approach was at the 'agreed' level. From the data analysis of individual items, the majority of the students agreed that "English critical reading comprehension has benefits for furthering higher education level" and they also agreed that "learning activities of English critical reading comprehension allowed them to have more opportunity for self-learning". This may result from them being upper secondary students and they are aware of the importance of higher education and self-autonomy and learning which may be a determining factor in their future careers. From the interviews with secondary students (upper level), they revealed that English critical reading comprehension is a necessary skill for several placement tests such as GAT, PAT, ONET, or TCAS. Another attitude that the students agreed with was that "they enjoyed learning and could gain knowledge from English 
critical reading comprehension teaching". This may be due to the implemented learning activities which encouraged them to think, pose questions, and seek for answers. This enabled them to be able to explore, study, express opinions, analyse, and apply by themselves that could be practiced through opinion expression sessions, debates, and online presentation.

\section{References}

Deborah J. Short 2011, "Research on academic literacy development in sheltered instruction Classrooms", Language Teaching Research, 15(3) p363-380

Holly Hansen-Thomas 2012, "Sheltered Instruction: Best Practices for ELLs in the Mainstream", Kappa Delta Pi Record: 44: 4, p165-169

Jana Echevarria, Catherine Richards-Tutor, Rebecca Canges and David Francis 2011, "Using the SIOP

Model to Promote the Acquisition of Language and Science Concepts with English Learners. Using the SIOP Model to Promote the Acquisition of Language and Science Concepts with English Learners", Bilingual Research Journal, 34:3, p334-351

Lawson, A. E. 1995, "Science Teaching and the Development of Thinking", Belmont : Wadsworth

Llewellyn, Douglas 2013, "Teaching High School Science Through Inquiry and Argumentation” 2nd ed. Corwin Pithulawan Supa-uthomporn 2016, "Effects of Using 5E Learning Cycle Model on Scientific Rational

Thinking Abilities and Scientific Creative Thinking Abilities of Lower Secondary School Students at Chulalongkorn University Demonstration Secondary School", Faculty of Education, Chulalongkorn University

Ruddell, M. R. 1997, "Teaching content reading and writing”, 2nd Edition, Needham Heights: Allyan \&Bacon Sydney, A. 2014, “The SIOP Model as it pertains to Ells in a Mainstream 2nd Grade Classroom", Master's thesis, St.Caterine University, Minnesota 